\title{
Factors that influenced mothers and/or caregivers in the Tshwane Metropolitan Municipality, South Africa, to purchase infant formula for their infants
}

\author{
Tshikovhi MP, RD(SA), MDietetics, Nutritionist, Nestlé South Africa \\ Gericke GJ, RD(SA), MDietetics, Head of Department \\ Department of Human Nutrition, Faculty of Health Sciences, University of Pretoria, Pretoria \\ Becker PJ, PhD, Biostatistician, Biostatistics Unit, Medical Research Council, Pretoria \\ Correspondence to: Madidimalo Tshikovhi, e-mail: diditshi@yahoo.com \\ Keywords: infant formula, breast milk substitute, formula feeds, breast milk, consumer behaviour
}

\section{Abstract}

Objective: The objective of the study was to identify and categorise factors that influence the choice behind the purchase of an infant formula brand by mothers and/or caregivers, and the reasons for their choice.

Design: This was a descriptive cross-sectional study in the quantitative research domain.

Setting: The setting was a pharmacy in Centurion Mall, and large food retail stores in Centurion Mall, Centurion Lifestyle Centre, Lyttleton Centre, Attlyn (Atteridgeville) and the Quagga Centre (Pretoria West) in Tshwane Metropolitan Municipality, South Africa.

Subjects and outcome measures: The 200 participants who were selected using purposive sampling completed a point-of-purchase questionnaire.

Results: The majority of the participants who purchased infant formula were aged 25-34 years, married, educated, affluent and employed full-time. Influencing factors were advice from others [ $76 \%$ (of which $32 \%$ was advice from a paediatrician)], a perceived claim that the infant formula provided a specific health benefit $(49.5 \%)$, brand loyalty $(13.5 \%)$, having seen an infant formula being used in hospital (10.5\%) and the infant's taste preference $(9 \%)$. Half of the participants $(51 \%)$ purchased infant formula manufactured by one of the largest manufacturers of this product globally.

Conclusion: Paediatricians' recommendations, as well as perceived health claims, were considered to be primary influencing factors with regard to the purchase of infant formula by mothers. Appropriate training should target paediatricians and other healthcare professionals to ensure that they advocate breastfeeding uncompromisingly, and advise mothers and/or caregivers on appropriate indications for infant formula.

(P) Peer reviewed. (Submitted: 2014-03-24 Accepted: 2014-10-25.) ๑ SAJCN

S Afr J Clin Nutr 2015;28(1):6-11

\section{Introduction}

Breast milk has been scientifically endorsed to be nutritionally and immunologically superior to infant formula, with an adequate amount and combination of macronutrients, micronutrients and immune factors for an infant's optimal growth and development. Breast milk is a nutritionally complete food for the first six months of an infant's life, and thereafter solids can be introduced and breastfeeding continued. ${ }^{1-4}$ Although breast milk is vital for healthy infants, a major concern globally is that women in South Africa and in other countries are continuously engaging in the contrary act of using breast milk substitutes, such as infant formula. There is a low prevalence, of only $8 \%$, of breastfeeding in South Africa. ${ }^{5,6}$

Thus, there was a need to investigate the factors that compel South African mothers to substitute, displace and complement breast milk, which is the best source of infant nutrition. According to the literature, little is known on factors that influence South African mothers and/or caregivers to purchase specific brands of infant formula. Therefore, this study aimed to identify those factors. Questions on why people choose one product or brand over another, and how they make these choices, can be answered by studying how consumers behave. ${ }^{7}$

\section{Research design}

The study was designed as a descriptive cross-sectional survey in the quantitative research domain. Interviews took place in a pharmacy in Centurion Mall, and in large food retail stores in Centurion Mall, Centurion Lifestyle Centre, Lyttleton Centre, Attlyn (Atteridgeville), and Quagga Centre (Pretoria West), which cater to the residents of Tshwane Metropolitan Municipality. The protocol was approved by the University of Pretoria's Faculty of Health Sciences Research Ethics Committee (Ref No. S214/2007). 
Table I: Health Action Model system ${ }^{8}$

\begin{tabular}{l|l|l|}
$\begin{array}{l}\text { System } \\
\text { Knowledge }\end{array}$ & Original questions & Questions modified to apply to the present study \\
\hline Normative & $\begin{array}{l}\text { What are the norms and rules followed in mushroom growing and } \\
\text { packing facilities? }\end{array}$ & $\begin{array}{l}\text { What do the consumers know about infant formula brands and } \\
\text { feeding practices? }\end{array}$ \\
\hline Motivational & What factors motivate the workers to follow food safety rules? & $\begin{array}{l}\text { What factors motivate or influence the consumers to purchase } \\
\text { formula? }\end{array}$ \\
\hline Food safety belief & $\begin{array}{l}\text { What are the workers' beliefs and attitudes about food safety and } \\
\text { food-borne illness? }\end{array}$ & $\begin{array}{l}\text { What are the consumers' beliefs and attitudes about the brands of } \\
\text { infant formula on the market? }\end{array}$ \\
\hline $\begin{array}{l}\text { The work site } \\
\text { (environmental) }\end{array}$ & What is the worker's working environment like? & What is the consumer's purchase environment like?
\end{tabular}

\begin{tabular}{|c|c|c|}
\hline $\begin{array}{l}\text { Individual factors } \\
\text { - Perception } \\
\text { - Motivation } \\
\text { - Learning } \\
\text { - Values, beliefs and attitudes } \\
\text { - Personality, self-concept and lifestyle }\end{array}$ & $\begin{array}{l}\text { Social factors } \\
\text { - Culture } \\
\text { - Reference groups, including opinion leaders and family } \\
\text { - Social class }\end{array}$ & $\begin{array}{l}\text { The purchase situation } \\
\text { - Purchase reason } \\
\text { - Purchase time } \\
\text { - Physical surroundings }\end{array}$ \\
\hline \multicolumn{3}{|c|}{ Consumer decision-making process } \\
\hline \multicolumn{3}{|c|}{ Buy or not buy } \\
\hline
\end{tabular}

Figure 1: A model of consumer behaviour ${ }^{9}$

\section{Sample}

Purposive sampling was used at the point of purchase. It was determined that a sample size of 196 participants, i.e. eight respondents for each of the 22 fundamental questions in the questionnaire, would adequately verify it, and thus a sample of 200 participants was selected. A participant was included in the study once she had selected infant formula with the intention of purchasing it, and having provided verbal consent to participate. The use of verbal consent was approved by the Faculty of Health Sciences Research Ethics Committee. Women who were sent to buy infant formula on behalf of others were not included in the study sample.

Sampling was carried out on Saturdays during peak hours, with the assumption that most South African companies and government offices do not operate on that day, giving employees an opportunity to shop and attend to family matters.

\section{Method}

\section{Development of the questionnaire}

A modified point-of-purchase questionnaire was used for data collection, and was based on the Health Action Model. The Health Action Model incorporates the Health Belief Model, and Ajez and Fishbein's theory of reasoned action. ${ }^{8}$ The questionnaire was developed as a comprehensive framework, and included major variables that have an influence on health choices and actions ${ }^{8}$ (Table I). The model within which the study was conducted was the Consumer Behaviour Model, and this model indicates the factors that affect the consumer decision-making process ${ }^{9}$ (Figure 1). The questionnaire also featured additional questions, included to test participants' under-standing of infant formula.

The content validity of the questionnaire was assessed by asking registered dietitians to complete and comment on the point-ofpurchase questionnaire. The face validity of the questionnaire was assessed by conducting a pilot study on 12 participants in the food retail stores and a pharmacy, similar to those selected for the main study, to ensure the clarity of the wording, comprehension and ease of completion.

\section{Data collection}

Data were collected by the researcher within a period not exceeding nine months (October 2007 to June 2008). Only participants who had consented verbally to take part in the study were asked to respond to questions on the point-of-purchase questionnaire. On average, a questionnaire was completed in five minutes. The pharmacy and the retail store management gave written consent to allow the researcher to stand in the infant formula aisle for the purpose of data collection. It was assumed that all of the participants tried their best to provide the most honest responses. 
Table II: The demographic characteristics of the participants $(n=200)$

\begin{tabular}{|c|c|c|}
\hline Demographic characteristics & $\mathbf{n}$ & $\%$ \\
\hline \multicolumn{3}{|l|}{ Age (years) } \\
\hline$<25$ & 22 & 11.0 \\
\hline $25-34$ & 134 & 67.0 \\
\hline$>35$ & 44 & 22.0 \\
\hline \multicolumn{3}{|l|}{ Ethnicity or race } \\
\hline African (black) & 66 & 33.0 \\
\hline Caucasian (white) & 82 & 41.0 \\
\hline Asian (Indian) & 47 & 23.5 \\
\hline Coloured & 5 & 2.5 \\
\hline \multicolumn{3}{|l|}{ Marital status } \\
\hline Single & 11 & 5.5 \\
\hline Single and living with extended family & 22 & 11.0 \\
\hline Married & 158 & 79.0 \\
\hline $\begin{array}{l}\text { Other (cohabiting, divorced, widowed, separated or } \\
\text { engaged) }\end{array}$ & 9 & 4.5 \\
\hline \multicolumn{3}{|l|}{ Highest education level } \\
\hline Grade 12, i.e. high school education and lower & 75 & 37.5 \\
\hline Diploma or certificate & 54 & 27.0 \\
\hline Degree or postgraduate qualification & 71 & 35.5 \\
\hline \multicolumn{3}{|l|}{ Combined family income per month } \\
\hline$\leq \mathrm{R} 6500$ & 18 & 9.0 \\
\hline R6 501-R16 500 & 42 & 21.0 \\
\hline$>$ R16 500 & 85 & 42.5 \\
\hline Wouldn't disclose the information & 34 & 17.0 \\
\hline Didn't know & 21 & 10.5 \\
\hline \multicolumn{3}{|l|}{ Current employment } \\
\hline Unemployed & 48 & 24.0 \\
\hline Full-time & 133 & 66.5 \\
\hline Part-time & 7 & 3.5 \\
\hline Self-employed & 8 & 4.0 \\
\hline Student & 4 & 2.0 \\
\hline \multicolumn{3}{|l|}{ Occupation } \\
\hline Housewives or homemakers & 46 & 23.0 \\
\hline Professional workers & 45 & 22.5 \\
\hline Management, business and financial workers & 34 & 17.0 \\
\hline Administrative support workers & 33 & 16.5 \\
\hline Sales workers & 11 & 5.5 \\
\hline $\begin{array}{l}\text { Service workers, except protective workers, e.g. } \\
\text { social workers }\end{array}$ & 11 & 5.5 \\
\hline Healthcare professionals & 10 & 5.0 \\
\hline Students & 4 & 2.0 \\
\hline Science, engineering and computer professionals & 3 & 1.5 \\
\hline Construction and extraction craft workers & 1 & 0.5 \\
\hline Casual employees & 1 & 0.5 \\
\hline Wouldn't disclose the information & 1 & 0.5 \\
\hline
\end{tabular}

To enhance the reliability of data collection, it was ensured that the interviews were conducted in a consistent manner by the researcher. Interviews were carried out at the point of purchase while the thought processes used in decision-making were still fresh in participants' minds.

\section{Data analysis}

Data were captured by the researcher using Microsoft ${ }^{\circledR}$ Excel $^{\circledR}$ and analysed using Stata Statistical Software ${ }^{\circledR}$ Release 10, 2007.

\section{Demographic characteristics of the participants}

Sixty-seven per cent $(n=134)$ of the mothers and/or caregivers who purchased infant formula were aged 25-34 years. Forty-one per cent $(n=82)$ were Caucasian and $33 \%(n=66)$ were African (Table II). The racial distribution was not intentional, but rather a representation of the participants who purchased infant formula for their infants.

Approximately one third of the participants (37.5\%) had completed either Grade 12 education or lower, 35.5\% had obtained either a Bachelor's degree or postgraduate qualification, and $27 \%$ had acquired either a diploma or a certificate. The majority of the participants (42\%) had a combined monthly family income of R16 500 and higher, and $66.5 \%$ were in full-time employment.

\section{Results}

\section{Factors that influenced participants' decisions to purchase infant formula for their infants}

Participants were allowed to choose a maximum of three factors which might have influenced their decision to purchase infant formula. Table III shows the percentage of participants who were influenced by various factors (ranked in order) when purchasing a specific brand of infant formula (column A), as well as the percentage of participants who claimed that a given factor had the greatest influence on their purchasing decision (column B). Advice received from others $(63 \%)$ was the factor with the greatest influence on a participant's decision to purchase infant formula. This was followed by the perception that a selected infant formula provided a specific health benefit $(6.5 \%)$.

\section{Purchased infant formula categorised according to the name of the manufacturing company}

Half of the interviewed participants (51\%) purchased manufacturer A's infant formula, one of the largest manufacturers of infant formula globally, followed by manufacturer $C(22 \%)$. The most frequently selected infant formula were two brands of infant formula by manufacturer $A(16 \%$ and $11 \%)$, one brand of infant formula by manufacturer $\mathrm{C}(10.5 \%)$, one brand of infant formula by manufacturer $B(7.50 \%)$, and another two brands of infant formula by manufacturer $A(6.50 \%$ and $6.50 \%)$ (Figure 2).

\section{The stage of infant formula in relation to the age of the child}

The types of infant formula which participants purchased corresponded well with the age of the child in the majority of cases. Ninety-four per cent of the participants $(n=76)$ whose infants were aged six months and younger purchased a starter infant formula. 
Table III: Factors that influenced participants to purchase a specific brand of infant formula $(n=200)$

\begin{tabular}{|c|c|c|}
\hline \multirow[t]{2}{*}{ Factor } & Column A & Column B \\
\hline & $\begin{array}{l}\text { The purchasing decision by participants was } \\
\text { influenced by this factor }(\%)^{*}\end{array}$ & $\begin{array}{l}\text { The number of participants who claimed that } \\
\text { this factor had the greatest influence on their } \\
\text { purchasing decision (\%) }\end{array}$ \\
\hline Because someone advised you to buy it ${ }^{*}$ & 76.0 & 63.0 \\
\hline Because it claims to provide a specific health benefit & 49.5 & 6.5 \\
\hline Other factors ${ }^{* *}$ & 48.0 & 10.0 \\
\hline Because you always buy it ${ }^{* * *}$ & 13.5 & 5.5 \\
\hline Because you have seen it being used in hospital & 10.5 & 7.5 \\
\hline Because your child likes it & 9.0 & 0.5 \\
\hline Because it is reasonably priced & 5.0 & 3.5 \\
\hline For convenience purposes & 3.0 & 0.5 \\
\hline Because of its nutrient composition & 2.0 & 0.5 \\
\hline Because it has been on the market for a long time & 1.5 & - \\
\hline Because of its labelling & 1.5 & 0.5 \\
\hline Because it is never out of stock & 1.0 & 1.0 \\
\hline $\begin{array}{l}\text { Because the product is free from certain ingredients, } \\
\text { e.g. cow's milk }\end{array}$ & 0.5 & - \\
\hline Because it was advertised & 0.5 & 0.5 \\
\hline Because it was on promotion or on special & 0.5 & 0.5 \\
\hline Because the packaging was appealing & - & - \\
\hline
\end{tabular}

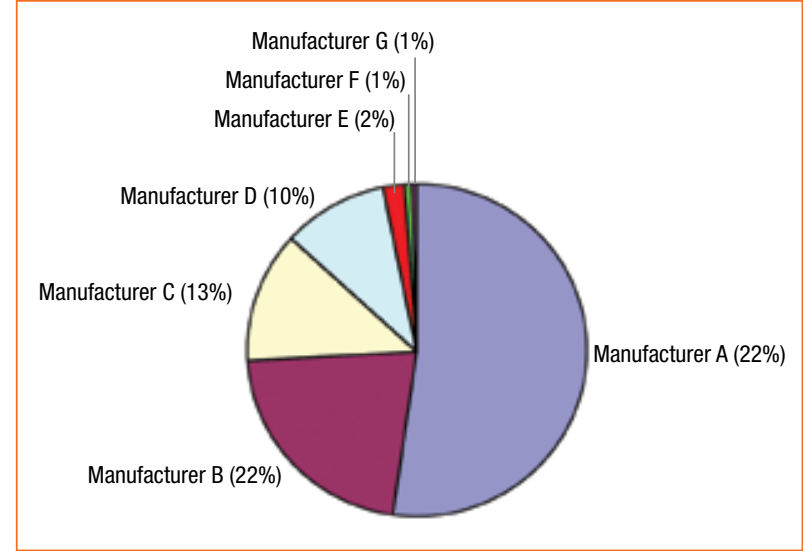

Figure 2: Infant formula purchased by the participants $(n=200)$, and categorised according to the name of the manufacturing company

Just over three quarters (88\%) of respondents whose infants were aged 7-12 months purchased follow-on formula. Only one child who was older than 12 months was still on a follow-on infant formula, instead of a "growing up milk". There was neither a starter nor follow-on infant formula to most of the "speciality" infant formula that was purchased. Therefore, the age of the infant was not taken into account in such cases.

\section{Discussion}

The factors that influenced mothers and/or caregivers to purchase specific brands of infant formula have been reported according to the Consumer Behaviour Model, which comprises individual factors (perception, motivation and learning), social factors (culture, reference groups and social class) and the purchase situation (the physical surroundings). These factors are known to affect purchase behaviour $^{9}$ (Figure 1). The association between the Health Action Model system and the Model of Consumer Behaviour is as follows: the knowledge system relates to individual and social factors, the normative system has similarities with the social factors, while the motivational system relates to the individual factors, social factors and the purchase situation. The food safety belief system pertains to some of the individual factors, and the work site environmental system relates to the consumer's physical surroundings (Figure 1, Table I).

\section{Individual factors (perception, motivation and learning)}

It was reported in a study carried out by Yee and Chin in East Malaysia that quality and brand were ranked the top two criteria in choice when choosing infant formula, and parents were found to be very quality oriented..$^{10}$ The second most influential reason why participants purchased infant formula was a perceived claim by its manufacturers that it provided a specific health benefit. This factor influenced almost one in every two participants (49.5\%) in the mentioned study. Both the present study and a Western Cape-based study by Sowden, Marais and Beukes reported that participants were influenced by the infant's medical condition and health claims, respectively, when deciding which infant formula to choose. ${ }^{11}$ The regulations relating to foodstuffs for infants and young children, which were published in 2012 by the South African Department of Health after data for the present study were collected, aim to control 
the labelling (health claims), composition, packaging, manufacturing, and sale and promotion of infant formula. ${ }^{2}$

The present study was conducted in 2007/2008 when the MotherBaby Friendly Initiative (MBFI) was still known as the Baby-Friendly Hospital Initiative. Implementation of the MBFI in South African mother and child health services, as per the recommendation of the World Health Organization (WHO) and United Nations Children's Fund, is the most likely explanation why the use of infant formula in hospital influenced only $10 \%$ of the participants during this period. This is different to the findings of a study performed in Ireland by Martyn, ${ }^{13}$ in which most of the women were influenced by a milk brand that they had seen in a hospital postnatal ward, making the hospital an advertising arena for infant formula. Yee and Chin also reported different results, indicating that promotional clauses had the highest impact on East Malaysian parents' decision to purchase a particular brand. ${ }^{10,13}$

Implementation of the MBFI and the International Code of Marketing of Breast-milk Substitutes may have been the reason why only a few participants in the present study were influenced by infant formula labelling $(1.5 \%)$, advertisements $(0.5 \%)$ and promotion $(0.5 \%)$. These initiatives prohibit the advertising and promotion of infant formula as the infant formula labelling portrays infant formula to be superior to breast milk. ${ }^{14}$ None of the participants was influenced by infant formula packaging.

\section{Social factors (culture, reference groups and social class)}

It was highlighted in a study on the mothers of infants carried out by Martyn that multiple personal factors had an impact them..$^{13}$ Three quarters of the participants in the present study were influenced by advice from others, and these findings concur with those reported by Yee and Chin, and Andrew and Harvey, namely that women reported that their infant feeding choices were influenced by the perceived norm among family and friends. ${ }^{10,15}$ Yee and Chin also reported that the opinions and advice of healthcare professionals were of great importance to women when making a decision to purchase infant formula. ${ }^{10}$

Three quarters of the participants in the present study received advice from others. Of these, a third was influenced by a paediatrician. A similar finding was reported by Sowden et al, who revealed that $63 \%$ of participants took the advice of their paediatrician. ${ }^{11}$ Hancock and Brown also reported that women recommend a paediatrician as a source of infant formula information. ${ }^{16}$

\section{The purchase situation (the physical surroundings)}

The absence of a specific brand of infant formula in a store influenced the decision-making process for two participants. It is suggested that the rest of the participants might be willing to shop around for the infant formula of their choice.

\section{Influencing factors that were not outlined in the Consumer Behaviour Model}

Influencing factors that were not outlined in the Consumer Behaviour Model, and which were part of the questionnaire used in the current study, are outlined herein. Sowden et al reported that $42 \%$ of the participants in their study were influenced by their child's preference, $38 \%$ by price and $62 \%$ by the composition of the infant formula. These findings are different to those in the present study in which the infant's preference $(9 \%)$, price $(5 \%)$ and infant formula composition (2\%) were not strong influencing factors with respect to participants' decision-making process when purchasing infant formula. ${ }^{11}$ The findings of the present study are in agreement with those of Yee and Chin in East Malaysia, in which children's preferences did not strongly influence parents' decisions when buying infant formula. ${ }^{10}$

Martyn also reported that almost all of the women in the study could buy an infant formula of their choice without being hindered by cost considerations. ${ }^{13}$ Parents were also reported to be willing to pay more for safer and quality-assured, powdered infant formula milk in a German study conducted by Goldberg, Roosen and Nayga. This indicates that price was not an influential factor, and this was also observed in the present study. ${ }^{13,17}$

Participants with a similar demographic profile (education level, ethnicity and combined monthly family income) were similarly influenced by a paediatrician's recommendation. Previous studies conducted by Point of Purchase Advertising International and DuPont in 1990 indicated that most purchase decisions are made in store and are unplanned, i.e. represent "impulse purchases", and that baby food was one of them. However, this finding is inconsistent with the results of the present study in which $95.5 \%$ of participants had the intention of purchasing infant formula before entering the store. ${ }^{18}$ Their planned purchases can be ascribed to the fact that a large percentage of them had already received advice from other people on what brand of infant formula to purchase.

Brand switching was reported by $25 \%$ of the participants. Both the present study and the study performed by Yee and Chin indicated that brand loyalty is motivated by the positive contribution of infant formula to the health of the infant. ${ }^{10}$

Nurses and paediatricians were the primary sources of information for general infant feeding for participants who claimed to have obtained enough information (advice) on the purchase of infant formula, whereas paediatricians were the primary source of information with regard to the choice of infant formula selected. Different results were reported by Lee. These indicated that British mothers did not receive enough information on infant formula from healthcare professionals when they needed it, and as a result, felt uncomfortable about feeding milk formula to their infants. ${ }^{19}$

The fact that only $41.5 \%$ of participants in this study believed in the existence of a superior infant formula indicates that most of them were aware that various brands of infant formula are available on the market to meet different individual infant needs. It is likely that such participants select the type and brand of infant formula that is appropriate to the particular needs of their own child. ${ }^{20}$

Participants with a low education level, i.e. Grade 12 and lower, incorrectly believed in the existence of a superior milk, whereas the majority of participants with a degree or postgraduate qualification were aware that this was not the case as different types of milk are used for meet different needs. The group whose participants had a lower educational qualification was probably less knowledgeable 
about infant formula than the group whose participants had a higher level of education.

\section{Conclusion}

A cross-sectional, point-of-purchase survey was conducted on 200 mothers and/or caregivers in Tshwane Metropolitan Municipality to identify and categorise factors that influence the choice behind the purchase of a specific infant formula brand by mothers, and the reasons for mothers' and/or caregivers' choice. The findings cannot be generalised because of the limited number of participants in the study. However, a variety of factors that influenced mothers and/ or caregivers to purchase specific brands of infant formula in the Tshwane Metropolitan Municiplality were identified.

A recommendation by a paediatrician had the greatest influence on the decision made by participants with a similar income and educational profile decision to purchase a specific infant formula.

It is recommended that future research should focus on:

- What influences paediatricians to recommend specific brands of infant formula.

- The sources of infant nutrition education and the type of breastfeeding-related information that paediatricians receive from government and/or training institutions.

- Whether or not paediatricians consider themselves to have enough information on infant nutrition.

- The relationship of paediatricians with infant formula manufacturing companies.

According to Article 4.1 of the WHO International Code of Marketing of Breast-milk Substitutes, it is the responsibility of government to ensure that objective and consistent information is provided on infant and young child feeding for use by families, and those involved in the field of nutrition for infants and young children. The main recommendation to the government of South Africa is that the superiority of breast milk over formula milk should be communicated to all healthcare professionals, including paediatricians in both public and private institutions.

\section{References}

1. Pediatrics American Academy of Pediatrics. Breastfeeding and the use of human milk. AAP [homepage on the Internet]. 2012. c2014. Available from: http://pediatrics. aappublications.org/content/129/3/e827.full.pdf+html
2. Roy SK, de Groot S, Shafique S, Afroz A. Perceptions of mothers and use of breastmilk substitutes in Dhaka, Bangladesh. J Health Popul Nutr. 2002;20(3):264-270.

3. Erick M. Nutrition in pregnancy and lactation. In: Mahan KL, Escott-Stump S, Raymond JL, editors. Krause's food, nutrition and diet therapy. $13^{\text {th }}$ ed. Missouri: Saunders, 2012; p. 366 .

4. Shabert JK. Nutrition during pregnancy and lactation. In: Mahan KL, Escott-Stump S, editors. Krause's food, nutrition and diet therapy. $11^{\text {th }}$ ed. Philadelphia: WB Saunders, 2000; p. 202.

5. The Tshwane declaration of support for breastfeeding in South Africa. S Afr J Clin Nutr. 2011;24(4):241

6. Department of Health, Medical Research Council, OrcMarco. South Africa Demographic and Health Survey 2003. [homepage on the Internet]. 2007 c2014. Available from: http:// www.measuredhs.com/pubs/pdf/FR206/FR206.pdf?_sm_au_=iVnt2VFsWMsSMc5

7. Consumer behaviour [homepage on the Internet]. c2014. Available from:

8. http://www-rohan.sdsu.edu/ renglish/370/notes/chapt05/

9. Nieto-Montenegro S, Brown JL, LaBorde LF. Development and assessment of pilot food safety educational materials and training strategies for Hispanic workers in the

10. mushroom industry using the Health Action Model. Science Direct [homepage on the Internet]. c2006. Available from http://extension.psu.edu/food/safety/publications/ foodcontrol 2008.pdf

11. Lamb CW, Hair FH, McDaniel C, et al. Marketing. Cape Town: Oxford University Press, 2008.

12. Yee CF, Chin R. Parental perception and attitudes on infant feeding practices and babymilk formula in East Malaysia. Int J Consumer Studies. 2007;31(4):363-370.

13. Sowden M, Marais D, Beukes R. Factors influencing high socio-economic class mothers' decision regarding formula-feeding practices in the Cape Metropole. S Afr J Clin Nutr. 2009;22(1):37-44.

14. Government Gazette. Regulations relating to foodstuffs for infants and young children. Pretoria: Government Printing Works, 2012

15. Martyn T. How mothers choose babymilk brands. Mod Midwife.1997;7(3):10-14

16. World Health Organization. International Code of Marketing of Breast-milk Substitutes. WHO [homepage on the Internet]. c2014. Available from: http://www.who.int/nutrition/ publications/code_english.pdf

17. Andrew N, Harvey K. Infant feeding choices: experience, self-identity and lifestyle. Matern Child Nutr. 2011;7(1):48-60.

18. Hancock ME, Brown J. What nurses need to teach parents who choose to formula-feed Nurs Women's Health. 2010;14(4):302-309.

19. Goldberg I, Roosen J, Nayga RM. Parental response to health risk information experimental results on willingness-to-pay for safer infant formula. Health Econ. 2009;18(5):503-518.

20. Wilkie WL. Consumer behaviour. $2^{\text {nd }}$ ed. New York: John Wiley \& Sons, 1990.

21. Lee E. Health, mortality, and infant feeding: British mothers' experiences of formula milk use in the early weeks. Sociol Health IIIn. 2007;29(7):1075-1090.

22. Dale J, Morrow AL. Choosing an infant or paediatric formula. J Pediatr Health Care. 2003;18(1):49-52. 